\title{
Artículo Especial: Historicismo clínico (o enfermedad histórica)
}

\author{
Esteban Rubinstein
}

\begin{abstract}
Resumen
En el contexto de una viñeta clínica, y basándose en su experiencia y en el concepto de "enfermedad histórica" propuesto por Nietzsche, el autor de este artículo propone una nueva categoría diagnóstica a la cual llama "historicismo clínico", caracterizada por la presencia de: 1) uno o más síntomas compatibles (angustia, cansancio, depresión, ideas rumiantes, insomnio, irritabilidad, falta de concentración, nihilismo, dolor crónico, disfunción sexual, otros síntomas inespecíficos, etc.), 2) el antecedente de un hecho histórico objetivo de carácter traumático, 3) el reconocimiento por parte de la persona afectada de estar aferrada a ese hecho histórico. La terapéutica propuesta se basa en dos premisas: 1) ayudar al paciente a encontrar herramientas (antídotos) para ponerle límite a la influencia del hecho histórico, así como el desarrollo de cierta capacidad para olvidarlo (o limitarlo) y 2) el estímulo de actividades creativas.
\end{abstract}

Palabras clave: enfermedad histórica, diagnóstico, tratamiento.

Rubinstein E. Historicismo clínico (o enfermedad histórica). Evid Act Práct Ambul. 2014, 17(2). Abr-Jun. 65-67.

El historicismo es una corriente de pensamiento que surgió en Alemania a mediados del siglo XIX y que sostiene que la naturaleza de las personas y de sus actos solamente es comprensible si se los considera como parte integrante de un proceso histórico. Nietzsche, en su libro Sobre utilidad y perjuicio de la historia para la vida ${ }^{1}$, reacciona contra esta corriente y acuña el término enfermedad histórica, al que considera sinónimo de historicismo. En dicho libro, el autor destaca los valiosos aportes que la ciencia histórica ha determinado en la vida de las personas, pero se dedica fundamentalmente a describir de qué manera esa misma ciencia histórica, cuando se la practica en exceso, puede devenir en historicismo (o enfermedad histórica) y, de ese modo, tener un efecto deletéreo sobre la vida.

Al leer la descripción de la enfermedad histórica que hace Nietzsche en su libro, me vinieron a la mente numerosas situaciones clínicas y pensé que estaba leyendo una definición minuciosa de un médico que ha descubierto una enfermedad nueva. Tras haber reflexionado lo suficiente, espero, acerca del significado de mis pasos futuros, me atreví a "tomar prestado" el concepto de enfermedad histórica definido por Nietzsche y adaptarlo a la práctica médica. Propongo, entonces, que consideremos la posible existencia de una enfermedad nueva, a la que denomino historicismo clínico (o enfermedad histórica), y que no es nueva porque antes no existía sino que es nueva porque antes no estaba descripta. Cabe mencionar que, a diferencia de uno de los objetivos de Nietzsche quien, al describir la enfermedad histórica, estaba alertando al lector acerca del peligro que esta representa para la vida, en mi caso no tengo el objetivo de asustar o alertar necesariamente a nadie, sino que pretendo que los médicos $y$, por consiguiente, los pacientes y la comunidad, tengan en cuenta esta posibilidad diagnóstica y, como veremos, las herramientas terapéuticas que pueden utilizarse, para evitar los eventuales daños que esta enfermedad puede ocasionarle a la salud. Obviamente, no puedo dejar de soslayar el hecho de que toda descripción implica una perspectiva (una mirada) y que es muy probable que mi descripción no sea ingenua.

Podríamos decir, entonces, que el historicismo clínico (o enfermedad histórica) es un problema de salud crónico en el cual la persona sufre de un exceso de historia, lo que determina que se vea afectada la fuerza plástica de su vida. Los síntomas más habituales mediante los que se manifiesta son: angustia, cansancio, depresión, ideas rumiantes, insomnio, irritabilidad, falta de concentración y nihilismo (creer que nada tiene sentido). Sin embargo, la sintomatología es proteiforme y pueden aparecer otros síntomas crónicos, tales como: dolores miofasciales, cefalea, disfunción sexual, dispepsia, mareos, parestesias, queja cognitiva, fracaso escolar y otros síntomas inespecíficos y/o difíciles de encuadrar dentro de una enfermedad definida.

Para que el historicismo clínico se desarrolle es preciso que el individuo afectado haya atravesado un hecho histórico determinado. A continuación se mencionan los hechos históricos que más frecuentemente favorecen el advenimiento de la enfermedad histórica: la muerte precoz del padre o de la madre (o de un ser querido), el antecedente de abuso sexual infantil o de violencia familiar, tener un familiar (habitualmente directo) con un problema psiquiátrico, una adicción compleja (como el alcoholismo) o una discapacidad, haber padecido (o tener un familiar que haya padecido) condiciones tales como violación, marginalidad, exilio, discriminación, prisión sin causa justa, abandono, estafa, violencia, persecución, secuestro, tortura, desaparición, muerte, holocausto, etc.

Para realizar el diagnóstico del historicismo clínico el médico debe apelar exclusivamente al interrogatorio ya que no existen estudios complementarios o tests para facilitarlo o determinarlo.

Las tres condiciones que deberían estar presentes son: 1) Presencia de uno o más síntomas compatibles (cualquiera de los descriptos arriba), 2) Antecedente de un hecho histórico y 3) Reconocimiento por parte de la persona afectada de estar aferrada a ese hecho histórico. Se recomienda que el diagnóstico se establezca mediante el consenso entre el médico y el paciente. Esto significa que, cuando el médico encuentra un paciente (o una familia) con estas características, sugiera la posibilidad de este diagnóstico y que sea el acuerdo entre ambos la circunstancia que defina la nominación de esta entidad como historicismo clínico o enfermedad histórica, y no la imposición del médico.

Veamos la siguiente viñeta clínica. Romina, de 26 años, ha venido ya varias veces a lo largo de cuatro años a la consulta médica, quejándose de mareos, cansancio, dispepsia y dolores miofasciales varios (en el cuello, en la región lumbar y en una rodilla). Vive con sus padres (ambos sanos) y está pensando en irse a vivir con el novio. Tiene una vida social activa, está por recibirse de contadora y trabaja como asistente en un estudio contable. No fuma, no toma alcohol en exceso, no consume drogas y no hace actividad física. En las consultas que tuvo conmigo intenté resolver los problemas que me fue trayendo, algunas veces con éxito y otras no tanto. En las charlas que he tenido, el único dato relevante que he recabado en el interrogatorio es que cuando Romina tenía seis años, su único hermano falleció de una leucemia aguda, a los ocho años, tras un año de una dura enfermedad. Este hecho histórico siempre apareció como un fondo de pantalla de su vida. Romina había buscado asistencia psicológica por su cuenta a los 20 años, pero no le sirvió, y la dejó. Después me pidió ayuda y le recomendé

‡ Servicio de Medicina Familiar y Comunitaria del Hospital Italiano de Buenos Aires. esteban.rubinstein@ hiba.org.ar 
realizar psicoterapia con una psicóloga y un psiquiatra que la ayudaron bastante a estar menos angustiada pero los síntomas persistían. Un día en que me consultó nuevamente por cansancio le pregunté si no sentía que estaba demasiado aferrada a la muerte de su hermano (al hecho histórico) y, tras contestarme que sí, le planteé la posibilidad del diagnóstico de historicismo clínico (o enfermedad histórica) y aceptó con entusiasmo mi propuesta diagnóstica.

Vemos aquí, entonces, en qué medida el diagnóstico de esta enfermedad es un proceso en el cual el médico va adentrándose paulatinamente, y al que solamente llega tras haber solicitado el consentimiento del paciente. En este sentido, cabe remarcar que hacer el diagnóstico de esta entidad (o enfermedad, o problema de salud) suele ser difícil por dos razones. Por un lado, el paciente convive con su problema desde hace mucho tiempo y, por lo tanto, en la mayoría de los casos lo tiene naturalizado (no es consciente de su enfermedad). Por otro lado, es muy habitual que los médicos no podamos detectar la presencia del historicismo clínico ya que estamos inmersos en dicha perspectiva. Con esto quiero decir que los médicos que atendemos a un paciente que ha sufrido un hecho histórico usualmente tendemos, mediante la compasión o la empatía, a asumir que dicho acontecimiento y el paciente forman parte de una misma unidad. En el ejemplo desarrollado arriba, probablemente para mí (y para los psicoterapeutas que la atendían) Romina era "la chica a la que se le murió el hermano cuando era chiquita" y, por lo tanto, me fue difícil pensar en la posibilidad de que hubiera un aferramiento a ese hecho histórico (y, por lo tanto, una situación tal vez poco saludable).

En cuanto al tratamiento de la enfermedad histórica, este se basa en que los médicos busquemos, en forma conjunta con el paciente, herramientas (antídotos es el término que utiliza Nietzsche) para ponerle límite a la influencia que tiene el hecho histórico deletéreo en su vida, sin que ello implique, necesariamente, negarlo, o rechazarlo, o dejar de valorarlo.

Uno de los antídotos para controlar la enfermedad está relacionado con el desarrollo de cierta capacidad para olvidar (o limitar) el hecho histórico.

Nietzsche es implacable cuando se refiere a las personas que no tienen capacidad para olvidar, y sus palabras pueden parecer muy duras a oídos poco acostumbrados a escuchar a este autor. Sin embargo, quiero volcarlas aquí, para luego llevarlas a la clínica. Nietzsche considera que sin la capacidad de olvido no puede haber ninguna felicidad, ninguna jovialidad, ninguna esperanza, ningún orgullo, ningún presente. El hombre en el que ese aparato de inhibición se halla deteriorado y deja de funcionar es comparable a un dispéptico (y no sólo comparable), ese hombre no "digiere" íntegramente nada (Genealogía de la moral ${ }^{2}$.

A mi juicio, la capacidad de olvidar puede adquirirse sin que eso implique, necesariamente, un "olvido total" (que, por otra parte, es imposible) y, nuevamente, tampoco una negación o desvalorización del hecho histórico.

Otro antídoto muy poderoso para contrarrestar los efectos nocivos del historicismo clínico sobre las fuerzas vitales (la fuerza plástica de la vida) es la capacidad de crear y de creer. La capacidad de crear puede ser estimulada por el médico o por cualquier integrante del personal de salud. Los ejemplos de las actividades relacionadas con dicha capacidad son: la creación artística, el trabajo creativo, el deporte, la actividad física, la participación en actividades sociales y/o culturales placenteras, etc. En cuanto a la capacidad de creer, aquí nos metemos en un terreno más complejo, pero tal vez los médicos podamos ayudar a algunos de nuestros pacientes a creer más en ellos, a tenerse más confianza y a confiar en su propio instinto y en sus propias creencias.

El tratamiento de las personas afectadas por la enfermedad histórica mediante la búsqueda, en forma conjunta con el paciente, de herramientas (antídotos) para ponerle límite a la influencia del hecho histórico, tales como el desarrollo de cierta capacidad para olvidarlo (o limitarlo) y el estímulo de actividades creativas es una tarea hermosa, desafiante y compleja que puede ser llevada a cabo por un médico u otro profesional de la salud y que puede ayudar a muchos pacientes. Para ello, es preciso contar con capacidad de escucha, no juzgar a la persona, contenerla, e ir acompañándola en el camino. No existe una técnica definida y cada profesional utilizará la que conoce y en la que cree, siguiendo los lineamientos arriba pautados.

Volviendo a la viñeta de Romina. Una vez planteado el diagnóstico, le ofrecí las siguientes medidas terapéuticas: 1) Con el objetivo de ayudarla a desarrollar cierta capacidad para olvidar (o limitar) el hecho histórico le planteé un ejercicio que suelo utilizar en estos casos. Le propuse que intentara imaginar que todas los recuerdos, pensamientos y sentimientos relacionados con la muerte de su hermano podían guardarse dentro de una pequeña gaveta (utilicé esta palabra, que es un sinónimo de un pequeño cajón, para evitar connotaciones mortuorias) que forma parte de un escritorio que tiene entre diez y veinte gavetas. La idea es que si ella logra decidir cuándo abrir y cuándo cerrar la gaveta donde está el hecho histórico tal vez logre limitarlo (olvidarlo), de algún modo, cuando la gaveta está cerrada y, de esta manera, evitar "ser" ese hecho por entero, y que este sea solamente "una parte de ella" y 2) Con el objetivo de ayudarla a desarrollar cierta capacidad de crear, dediqué varias consultas a hurgar en sus gustos personales y apareció su gusto por el vóley, un deporte que había realizado en su infancia durante dos años. La ayudé a buscar un club donde se jugaba vóley en forma amateur y comenzó a ir dos veces por semana a un club barrial. Al cabo de pocas semanas, Romina comenzó a estar más alegre y menos cansada y, al cabo de un año, las consultas se espaciaron y los síntomas casi desaparecieron. Actualmente ya terminó su tratamiento psicoterapéutico y me ve muy poco. Cuando me visitó el otro día para que le firmara un certificado de aptitud física para presentar en el club me dijo, sonriendo, que andaba muy bien de su enfermedad histórica.

Dudé mucho en volcar en este texto el ejemplo de Romina ya que los médicos solemos describir nuevos paradigmas con éxitos terapéuticos donde todo parece ser color de rosa, mientras que todos sabemos que hay pacientes a quienes el diagnóstico y las herramientas terapéuticas les sirven, a otros no les sirven y a otros incluso pueden dañarlos.

En realidad me parece que en este punto vale la pena detenerse a pensar en los riesgos que tiene definir una nueva enfermedad. Siempre he estado del lado de quienes cuestionan la creación de enfermedades donde no las hay (disease mongering) y vengo intentando desde hace tiempo que los médicos "ablandemos" nuestro lenguaje cuando nos referimos a las enfermedades que diagnosticamos, sobre todo en las personas asintomáticas. En ese sentido, me pregunto qué implicancias puede tener para la salud de las personas la existencia del término historicismo clínico. Seguramente existen desventajas, y pese a que me sigue pareciendo riesgoso acuñar una nueva enfermedad, creo haber reflexionado lo suficiente como para hacerlo, con el convencimiento de que las ventajas son mayores que las desventajas. 
Las ventajas que le encuentro a la existencia del historicismo clínico como nuevo paradigma diagnóstico están desarrolladas en este texto y básicamente se resumen en el hecho de que, al conocer el diagnóstico y el tratamiento, los profesionales de la salud tal vez estamos mejor preparados para aliviar los síntomas crónicos de algunos pacientes. Me interesa especialmente el lugar que podemos ocupar los médicos (y otros profesionales de la salud) para ayudar a los pacientes que tienen enfermedad histórica a desarrollar cierta capacidad de crear. Tal vez, debo reconocerlo, este es el punto que más me apasiona de este proceso. En este sentido, a medida que voy profundizando en esta sencilla y alegre herramienta terapéutica, cada vez estoy más convencido de que para que esa capacidad creativa (deporte, arte, etc.) sea beneficiosa para la salud, esta debe relacionarse con los otros. Los otros son los profesores (de gimnasia, de canto, de dibujo, etc.) y los compañeros (de vóley, de grupo de corredores, de teatro, etc.) que es preciso buscar y encontrar para encarar dicha tarea creativa. Ellos son, a mi juicio, los vectores que facilitan, y sobre todo sostienen a lo largo del tiempo, la salida del nihilismo en el que dormitan las personas con enfermedad histórica y que les permite reencontrarse con la alegría.

Otra ventaja posible de que el diagnóstico de la enfermedad histórica exista es que, a mi juicio, el encuadre profesional (tanto por parte de los médicos como de los psicólogos) de algunas personas con esta enfermedad puede perpetuar los síntomas, e incluso exacerbarlos, si sigue soslayándose el diagnóstico (y los diagnósticos solamente pueden soslayarse si están descriptos). Este es un tema complejo, que está relacionado con las ventajas y desventajas de "dar un diagnóstico" y que prefiero no desarrollar aquí (pero dejo aclarada mi postura de que solamente tiene sentido ponerle un nombre a los problemas de salud cuando las acciones que surgen de ese acto son beneficiosas).

Independientemente de las premisas mencionadas, cabe mencionar que en las personas que tienen historicismo clínico la ayuda profesional no es imprescindible ya que, como ocurre con muchos problemas de salud, hay personas que mejoran solas o que encaran cambios por sí mismas, o ayudadas por familiares, amigos, compañeros de trabajo, etc. Sin embargo, a mi juicio, como ya mencioné, la ayuda es bienvenida.

Por último, es importante tener en cuenta que los hechos históricos no son, en rigor, ni buenos, ni malos, simplemente son eventos que ocurrieron (o que pueden estar ocurriendo, como sucede con las personas cuyo hecho histórico es tener un familiar con un problema psiquiátrico) y que pueden ser útiles o nocivos para la vida. Tal vez uno pueda parangonar el historicismo clínico con la alergia o con las enfermedades autoinmunes: podría decirse que la respuesta inmune (el hecho histórico) usualmente es beneficiosa para la vida, pero que su exceso puede causar daño y dar lugar a entidades como la alergia y las enfermedades autoinmunes (el historicismo clínico).

Referencias:

1. Nietzsche F. Sobre utilidad y perjuicio de la historia para la vida. Córdoba: Alción Editora; 1998.

2. Nietzsche F. La genealogía de la moral. Buenos Aires: Alianza Editorial; 2008. 